\title{
SUMOTORI: A NETSUKE THAT DOES NOT FIT OUR PARADIGM
}

Collecting netsuke is a joy, not just because of the beauty of the carvings but also because of the stories behind the subject chosen by the carvers. ${ }^{1}$ Usually the subject is readily discernible, but every now and then an enigmatic example is encountered. The netsuke discussed in this essay clearly represents a wrestler, but in no way resembles our idea of a sumo wrestler (rikishi or, more popularly, sumotori) and, because of this, we initially had problems categorising this figure. Sumo is known in the West as a wrestling sport where two overweight colossi try to push each other to the ground or out of a ring. However, this is a rather superficial understanding, which does not acknowledge that sumo belongs to the oldest indigenous aspects of Japanese culture. The purpose of this essay is to provide some historical background to sumo in order to view our netsuke from the proper iconographic perspective.

\section{The netsuke}

Figure I shows an early igth-century elephant ivory netsuke of a standing man, with his right leg crossed in front of his left and his head turned to the right. He is dressed in a long-sleeved, short tunic that is open in front exposing his chest and belly. He wears a loincloth, held by a broad belt tied in a bow on his back, with an apron in front decorated with a Buddhist shishi ('lion') mask. His right arm is along his side with the hand resting on the belt. In his left hand he holds a sword, at shoulder height, pointed downwards with the tip tucked under his belt. He has a round face and his hair is pulled back in a topknot. On his back at shoulder height is a character that reads $a k u$ ('bad' or 'evil'). By his feet a threelegged toad (with two hind legs!) seems to be trying to climb up his leg. The himotoshi (the cord channel through which cord is pulled to connect the netsuke to the hanging object) is on his back, comprising two holes of unequal size ( 4 and $5 \mathrm{~mm}$ ). The inner surface of the larger hole bears a signature, now illegible due to wear, within an oval reserve.

\section{A summary of the history of sumo}

Martial arts similar to sumo have been practised around the world for centuries and some still are today, for example, in South Korea, Mongolia and Turkey, but Japan is the only country where it has developed into a professional sport. There are several reasons for this. Firstly, according to

Fig. 1a (right)

A standing samurai, netsuke, ivory, h. $7.5 \mathrm{~cm}$, Japan, early 19th century, private collection Japanese mythology sumo wrestling originated as a hand-to-hand tussle between two deities. Secondly, from its historical beginnings sumo had a ceremonial meaning deeply embedded in the Shinto religion. And thirdly, sumo appealed particularly as a martial art during the samurai era, where physical strength and man-to-man combat Dyere held in high esteempers/2023 02:52:50Am 


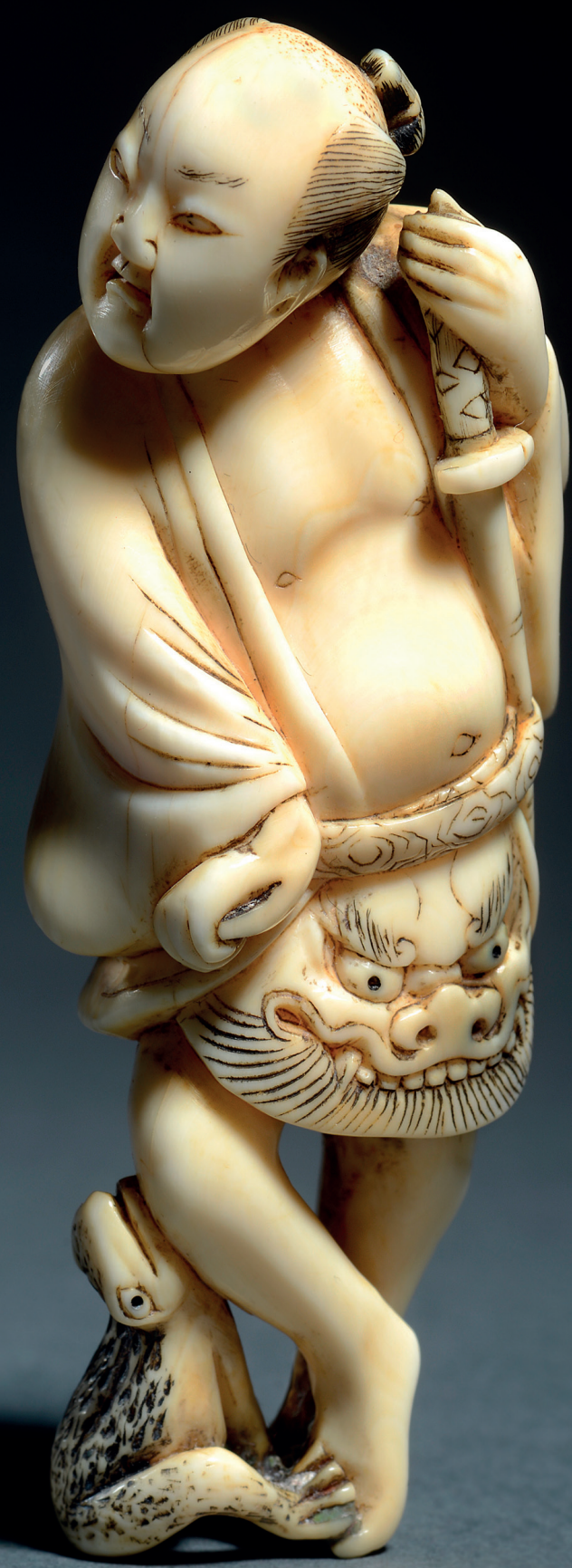




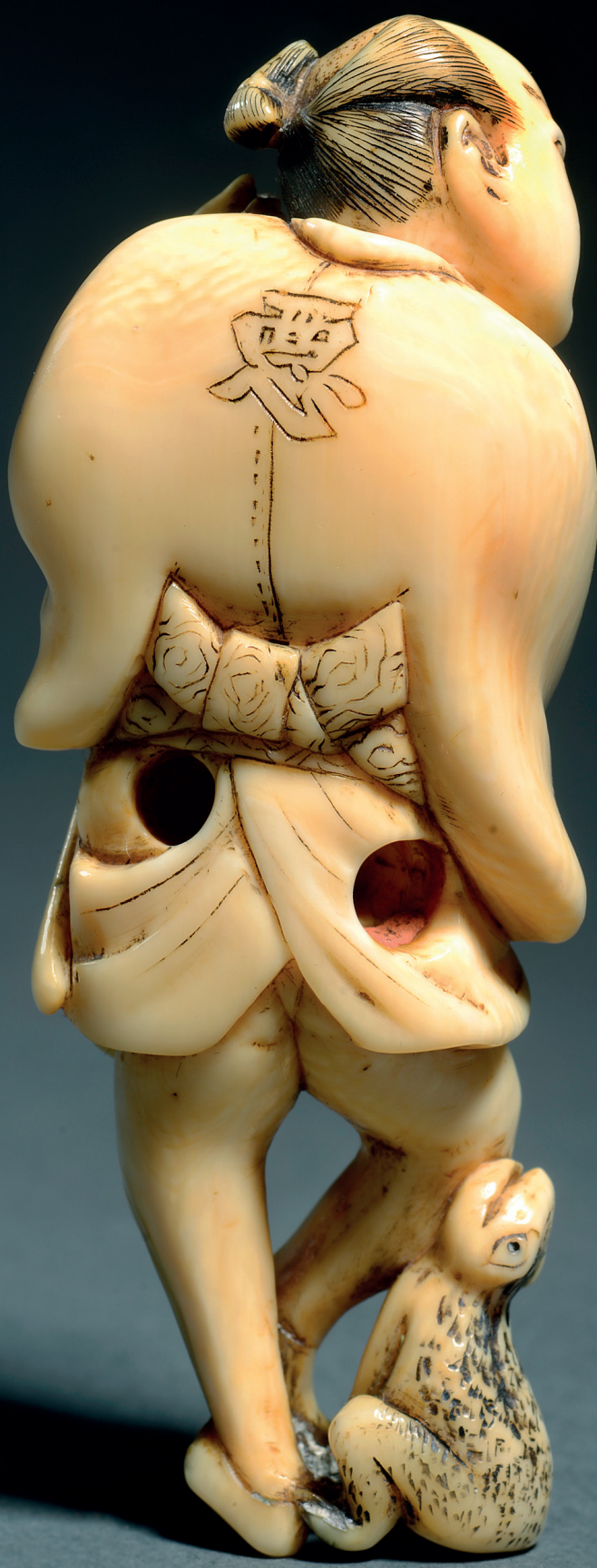


Fig. 1b (left)

Reverse with himotoshi (4 and $5 \mathrm{~mm}$ )
Fig. 2

A late 18th-century ivory manju netsuke showing two sumotori, carved in deep relief. The one in front, seen from behind, has lifted his opponent by the belt. The latter has hooked his left leg behind his opponent's left leg, a position known as kawazu gake ('one leg entanglement drop')
It is impossible to identify when exactly sumo initially appeared in Japan, but the sport is mentioned in the myths and legends of the Kojiki and the Nihon Shoki, ${ }^{2}$ both written in the first half of the eighth century. The first sumo matches, called shinji-zumo, were held in the grounds of local shrines and had a religious function. They were intended to please the gods and as prayers for bountiful crops. During the Nara period (646794) shinji-zumo evolved into a national pastime with yearly tournaments at the Imperial court. In the succeeding Heian period (794-II85) the religious associations remained, but sumo matches also evolved into a form of entertainment at the court, called sumai no sechie. The end of the Heian period also brought an end to the political power of the emperors and with it also their influence on sumo. The samurai class ruled Japan during the ensuing Kamakura period (II85-I336). Subsequently, although the samurai embraced sumo as the perfect form of man-to-man combat, precisely as their military tradition dictated, the large sumo tournaments at the Imperial court ceased, resulting in a gradual decline of sumo. Because of the lack of government support, sumo events were only organised at a local level. During the Muromachi period (I336-I568) these circumstances led to the organisation of so-called kanjin-zumo, sumo matches held to raise money for the upkeep of shrines and temples. The first professional sumo wrestlers appeared during this period, usually samurai without a master (so-called ronin), who participated in the kanjin-zumo and were paid from the earnings of the bout.

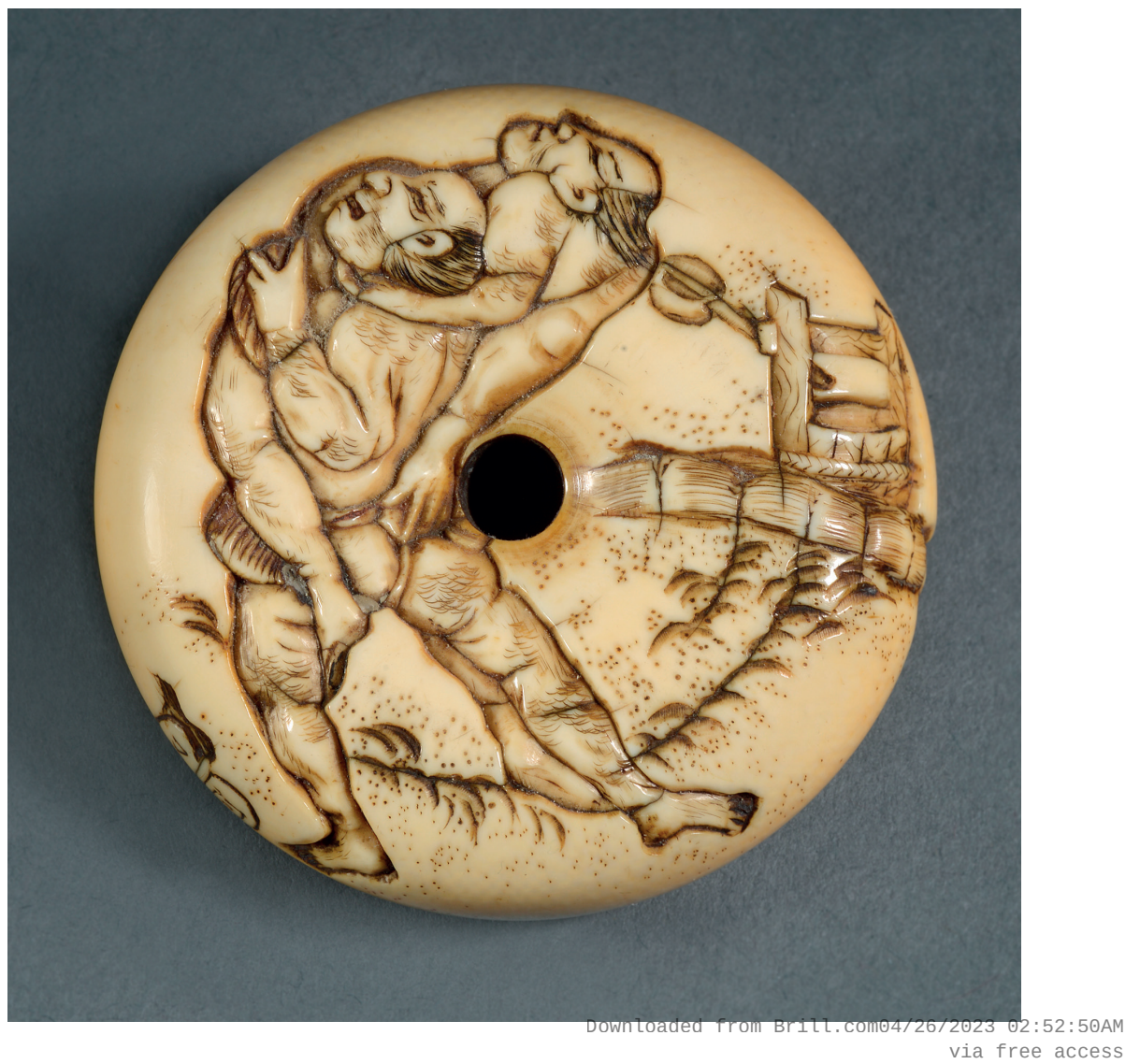



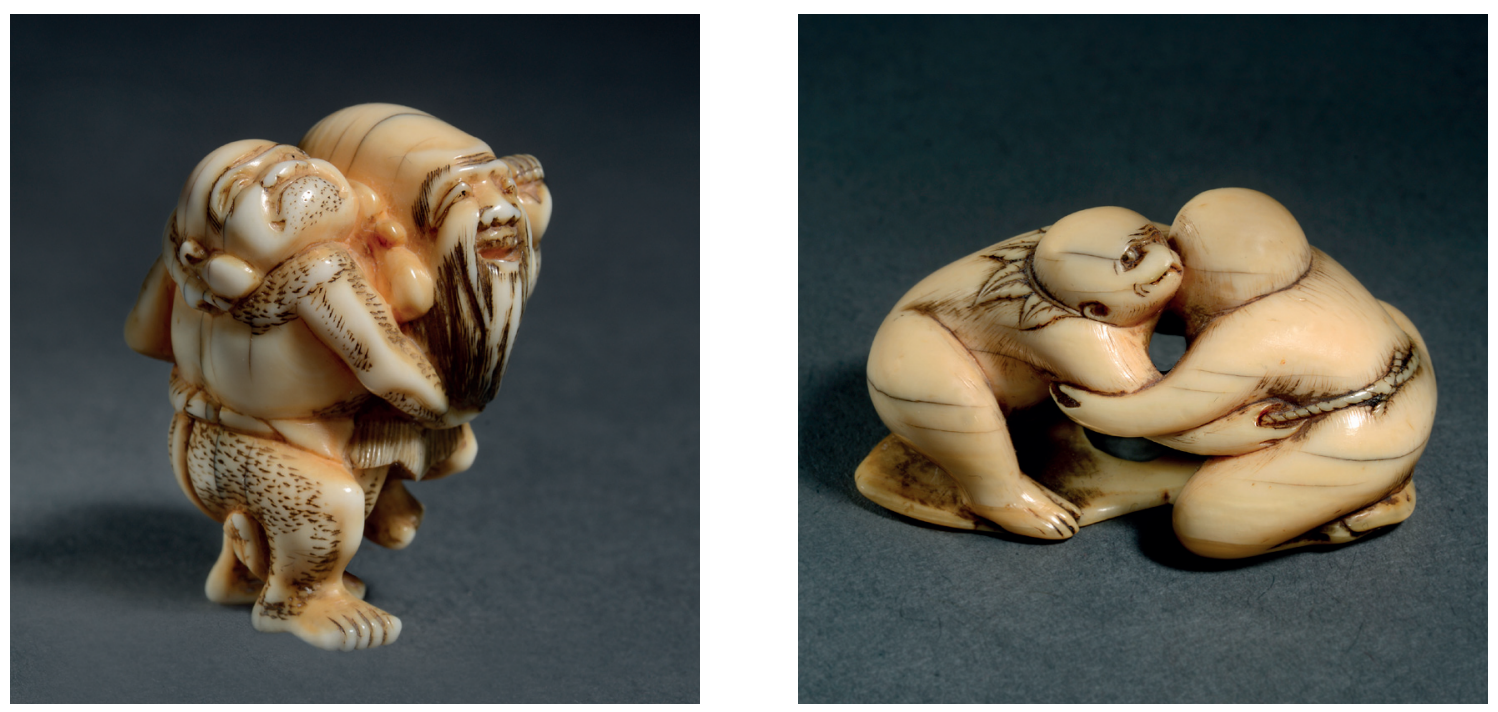

Fig. 3 (left)

A late 18th- to early 19th-century ivory netsuke, h. $8 \mathrm{~cm}$, showing two deities, Hotei and Fukurokuju, locked in the kawazu gake hold. Shinto gods are often displayed in humorous or satiric poses

Fig. 4 (right) An early 19th-century ivory netsuke, 4 X $2.7 \times$ $2.3 \mathrm{~cm}$, representing two monkeys in a sumo bout. The subject is most likely based on the Chōjū-giga ('Scrolls of Frolicking Animals and Humans', 12th-13th century)
During the Tokugawa (Edo) period (I603-I868), a time of peace and prosperity, increasing numbers of samurai had no work and roamed the country without any direct allegiance to a feudal master; to all intents and purposes they were outcasts who often had little respect for the law. Because of these deplorable conditions, many ronin turned to sumo as a means of earning a living. Hence, the number of sumotori rose dramatically in this period and the charitable nature of the kanji-zumo was slowly replaced by events that only benefitted the wrestlers. This caused a further decline in the standards of sumo, leading to matches organised on the streets, so-called tsuji-zumo, or 'street corner sumo'. These developments inevitably led to unwanted situations such as gambling, disputes and riots; to such an extent that the ruling shogun banned sumo twice, in I648 and again in I66I. In the meantime however, sumo had become so popular among the wider population that the prohibitions could not be enforced and eventually in I684 the shogun granted permission for an official sumo tournament. This event was very successful and actually turned out to be the start of the revival of sumo as a sport in Japan. It is not surprising therefore, that sumo also became a popular subject for netsuke carvers (see figs. 2, 3, 4).

In recent years, sumo has again been brought into disrepute by all sorts of scandals such as match fixing and the deplorable conditions at some of the sumo stables. Moreover, Japanese pride was insulted when foreigners - Hawaiians and Mongolians - won all the important tournaments. At present there are three Yokozuna (Grand Champions), but all three are Mongolian. However, after a decade-long wait, the Emperor's Cup at the New Year Grand Sumo Tournament in Tokyo (January 20I6) was finally won by a Japanese, Kotoshogiku, an Ozeki (the second highest rank in sumo) and Japan's main hope for a Japanese Yokgzung in the near future 02:52:50Am 


\section{Back to our netsuke}

Our netsuke depicts a slender and athletic figure who does not fit our contemporary stereotype of an overweight colossus. The history of sumo reveals that in the igth century, when our netsuke was carved, increasing numbers of sumo wrestlers were recruited from among the ronin.

In fact, the sword carried by our wrestler is a clear indication of his earlier status as a samurai. The $a k u$ character on his back may well refer to his lawless lifestyle as a ronin prior to turning to sumo. The symbolism of the three-legged toad at his feet can be seen as a subtle humorous touch by the carver and is interesting since these mythical creatures are often associated with supernatural powers and immortality, which after all are not bad qualities for a sumo wrestler.

Our netsuke further illustrates that the accurate categorisation of netsuke necessitates at least some understanding of the historical background of the subject chosen by the carvers.

- Ton and Mies Becker both worked as pathologists and started to collect Asian art objects, including a large collection of netsuke, in the I97os. They published a book in 20I2, IOI Netsuke: Japanese Toggles from the Treasure Farm / Japanse gordelknoop miniaturen uit de Schattenstolp.

\section{LIT E RAT URE}

Rosemary Bandini, Tiny Titans: The Sumo Netsuke Collection of Karl-Ludwig Kley, British Library Cataloguing-in-Publication Data, 2006.

Lawrence Bickford, Sumo and the Woodblock Print Masters, Kodansha International, Tokyo, 1994.

David Shapiro, Sumo: A Pocket Guide, Charles E. Turtle Publishing Co., Inc. Rutland, Vermont \& Tokyo, Japan, 1995. [revised edition]

\section{ELECTRONIC SOURCES}

https://en.wikipedia.org/wiki/kojiki (accessed 23 March 20I6)

https://en.wikipedia.org/wiki/nihon_shoki (accessed 23 March 20I6)

\section{NOTES}

* Photographs by Ferry Herrebrugh.

I A netsuke is a Japanese toggle, a carved button-like ornament, usually of ivory or wood, sometimes metal or ceramic, formerly worn in Japan to hang small personal belongings from the sash of a kimono (which had no pockets).

2 The Kojiki ('Records of Ancient Matters') is the oldest extant chronicle in Japan, dating from 7II-7I2. It consists of a collection of myths concerning the origin of the main islands of Japan and its relationship with the Kami (gods). The Nihon Shoki ('The Chronicles of Japan') is the second oldest book of classical Japanese history, completed in 720 , and is more elaborate and detailed than the Kojiki. 